\title{
Analisis Minimisasi Biaya Amlodipin Generik dan Bermerk pada Pengobatan Hipertensi di RS X Pekanbaru Tahun 2015
}

\section{Cost Minimization Analysis of Generic and Branded Amlodipin in Hypertension Treatment at X Pekanbaru Hospital 2015}

\author{
Hanny Merliana', Amal Chalik Sjaaf ${ }^{2}$ \\ ${ }^{1}$ Kajian Administrasi Rumah Sakit, Fakultas Kesehatan Masyarakat, Universitas Indonesia, Depok, Indonesia \\ ${ }^{2}$ Departemen Administrasi dan Kebijakan Kesehatan, Fakultas Kesehatan Masyarakat, Universitas Indonesia, Depok, Indonesia \\ Korespondensi: Hanny Merliana, \\ e-mail: hanny.merliana@yahoo.co.id
}

\begin{abstract}
Abstrak
Hipertensi merupakan tantangan besar di Indonesia, berdasarkan data Riskesdas 2013 prevalensi kejadian sebesar 25\% serta kondisi yang sering ditemukan pada pelayanan kesehatan primer. Disamping itu, pengontrolan hipertensi belum adekuat meskipun obat-obatan yang efektif banyak tersedia. Amlodipine adalah salah satu obat hipertensi yang paling sering diresepkan di RS X Pekanbaru. Untuk itu,dipandang perlumelakukan analisis minimisasi biaya dari pengggunaan amlodipine generik dan bermerek sebagai bentuk kendali mutu dan kendali biaya.Penelitian ini merupakan studi retrospektif yangmenggunakan data pasien hipertensi ringan sampai sedang dan periode pengobatan selama 1 bulan dari bulan Januari sampai Desember tahun 2015. Analisa CMA berdasarkan perspektif provider (rumah sakit sebagai pemberi pelayanan). Hasil analisis data ditemukan bahwa penggunaan amlodipin generik lebih banyak dibandingkan penggunaan obat bermerk di Poli Jantung dan Penyakit Dalam RS. X.Rerata biaya pengobatan dengan amlodipin generik Rp 68.660,- per bulan sedangkan dengan amlodipin bermerk sebesar Rp. 374.844.- atau sekitar 5,4 kali lebih tinggi dari amlodipin generik. Penggunaan amlodipin generik maupun bermerk menurukan tekanan darah secara bermakna, namun tidak terdapat perbedaan bermakna antas penurunan tekanan darah yang dicapai dengan pemberian amlodipin generik maupun amlodipin bermerk. Disimpulkan bahwa amlodipin generik merupakan pilihan yang efisien dalam menurunkan tekanan darah dan memiliki biaya yang lebih efisien dibandingkan dengan amlodipin bermerk.

Kata kunci : amlodipin; generik;analisis minimisasi biaya;hipertensi; rumah sakit
\end{abstract}

\begin{abstract}
Hypertension in a big challenge in Indonesia, proven by its prevalence that reached 25\% in 2013 and conditions that mostly found in primary health care. In addition, hypertension management is considered to be suboptimal despite the availability of effective drugs. Amlodipine is one of anti-hypertensive that is commonly prescribed by X Hospital, Pekan Baru. Therefore, it is important to do cost minimization analysis to compare both generic and branded Amlodipine as an implementation of cost and quality control. This retrospective study involved early and medium stage of hypertensive patients that have at least a month period of treatment from January to December 2015 using provider's perspectives of CMA (Cost Minimization Analysis). The result showed that generic form of Amlodipine is the most common anti-hypertensive drugs prescribed in Cardiology and Internal Medicine Clinic, X Hospital. It was suggested that average cost of generic form of Amlodipine was IDR 68.660 while branded one was IDR 374.844 or approximately 5.4 times higher. Both generic and branded Amlodipine significantly reduced blood pressure, but there was not any distinguish effect between them. It was concluded that generic form of Amlodipine was a less expensive and efficient choice in reducing blood pressure. Key words: Amlodipine; generic; cost minimization analysis; hypertension; hospital
\end{abstract}

\section{Pendahuluan}

Sejak diimplementasikannya Jaminan Kesehatan Nasional (JKN) diawal tahun 2014, pola pembiayaan kesehatan di Indonesia mengalami perubahan. Termasuk perubahan konsep pembayaran fee for service di Rumah Sakit menjadi sistem paket pembayaran dengan menggunakan INA-CBG's. Rumah sakit harus memiliki strategi dalam menghadapi perubahan tersebut sebagai bentuk kendali mutu dan kendali biaya dalam memberikan pelayanan kesehatan.

Hipertensi merupakan tantangan besar di Indonesia, berdasarkan data Riskesdas 2013 prevalen- si kejadian sebesar 25\% serta kondisi yang sering ditemukan pada pelayanan kesehatan primer. Disamping itu, pengontrolan hipertensi belum adekuat meskipun obat-obatan yang efektif banyak tersedia.

Terkait dengan hal tersebut, disadari bahwa obat antihipertensi merupakan kategori obat yang tergolong vital,dengan tingginya biaya yang diperlukan (high cost) karena penggunaannya yang dalam waktupanjang dan volume penggunaannya yang tinggi. Seperti halnya di pusat-pusat pelayanan kesehatan di Indonesia, hipertensi juga termasuk kedalam salah satu sepuluh besar penyakit terbanyak di RS X Pe- 
kanbaru. Obat antihipertensi yang paling sering diresepkan di RS X Pekanbaru adalah Amlodipine.

Berdasarkan hal tersebut diatas, maka dipandang perlu untuk dilakukan analisis minimisasi biaya obat antihipertensi Amlodipine dengan membandingkan produk amlodipin generik dan bermerk yang terdapat dalam formularium RS X Pekanbaru. Pemilihan ini didasari ataspemahaman bahwa setiap produk amlodipin baik itu generik maupun bermerk telah memiliki kesetaraan yang dibuktikan dengan uji BA/BE (BioAvailabilitas/BioEkivalensi) yang dimiliki masing-masing produk. Dengan demikian, seharusnya amlodipin generik dan bermerk memiliki efektivitas yang sama. Namun, pada kenyataannya terdapat perbedaan harga yang besar dari keduajenis obat ini.

Dalam studi yang dilakukan oleh Alefan Qais et al, pada tahun 2009, obat antihipertensi menyumbang 53,7 persen, 55,1 persen dan 72,4 persen dari prehipertensi, tahap 1 dan tahap 2 kelompok hipertensi dari total biaya medis langsung. Biaya obat adalah pemicu biaya utama dari total biaya. Studi biaya ini menyatakan terdapat asosiasi positif antara tekanan darah dan biaya medis bulanan pribadi. Namun, biaya medis yang timbul dikombinasikan pra-hipertensi dan tahap 1 hipertensi yang lebih tinggi daripada yang disebabkan tahap 2 hipertensi. Jumlah biaya langsung yang meningkat berbanding lurus dengan peningkatan tekanan darah seperti yang dimuat dalam Asian Journal of Pharmaceutical and Clinical Research.

Analisis minimisasi Biaya/Cost Minimization Analysis (AmiB/CMA) : Membandingkan dua atau lebih pilihan dengan tingkat efektivitas yang sama, untuk mencari mana yang membutuhkan sumber daya paling sedikit. Merupakan teknik yang didesain untuk melakukan pilihan diantara beberapa alternatif yang mungkin dilakukan dengan mendapatkan outcome yang setara dengan melakukan identifikasi biaya yang dibutuhkan atau dikeluarkan dari alternatif-alternatif tersebut. Salah satu evaluasi farmakoekonomi adalahanalisis minimalisasi biaya yang merupakan metode kajian farmakoekonomi paling sederhana, analisis minimalisasi-biaya hanya dapat digunakan untuk membandingkan dua atau lebih intervensi kesehatan, termasuk obat, yang memberikan hasil yang sama, serupa, atau setara atau dapat diasumsikan setara.Karena hasil pengobatan dari intervensi (diasumsikan) sama, yang perlu dibandingkan hanya satu sisi, yaitu biaya (Walley,
Haycox, 1991).

Jika dua terapi atau dua (jenis, merek) obat setara secara klinis, yang perlu dibandingkan hanya biaya untuk melakukan intervensi. Sesuai prinsip efisiensi ekonomi, jenis atau merek obat yang menjanjikan nilai terbaik adalah yang membutuhkan biaya paling kecil per periode terapi yang harus dikeluarkan untuk mencapai efek yang diharapkan. Untuk membandingkan dua atau lebih intervensi kesehatan yang memberikan besaran efek berbeda, dapat digunakan analisis efektivitas biaya (AEB). Analisis minimalisasi biaya adalah tipe analisis untuk menentukan biaya program terendah dengan asumsi besarnya manfaat yang diperoleh sama. Analisis ini digunakan untuk menguji biaya relatif yang dihubungkan dengan intervensi yang sama dalam bentuk hasil yang diperoleh. Kekurangan yang nyata dari analisis minimalisasi biaya adalah asumsi pengobatan dengan hasil harus ekivalen. Jika asumsi tidak benar dapat menjadi tidak akurat. Pada akhirnya studi dapat menjadi tidak bernilai. Pendapat kritis analisis minimalisasi biaya hanya ditujukan untuk prosedur hasil pengobatan yang sama (Vogenberg, 2001; Walley, 2004).

\section{Metodologi Penelitian}

Studi ini menggunakan metode cross sectional antara obat antihipertensi dengan zat aktif amlodipin produk generik dan bermerk untuk mengetahui biaya obat-obat tersebut selama rentang waktu 1 (satu) bulan dengan sampel seluruh pasien yang berkunjung ke Poliklinik Penyakit Dalam dan Jantung dalam bulan Januari sampai Desember 2015 dan mendapatkan terapi antihipertensi amlodipin dalam bentuk produk generik dan bermerk. Sampel dipilih berdasarkan metode consecutive sampling dan analisis data hingga tahap bivariat. Biaya dihitung berdasarkan perspektif rumah sakit sebagai pemberi pelayanan kesehatan.

\section{Hasil Penelitian}

Dari total 170 subyek penelitian yang menggunakan anti-hipertensi amlodipin generik maupun bermerk, hanya 139 yang memenuhi persyaratan kriteria inklusi. Sebanyak 12 kasus tidak memenuhi kriteria sebab memiliki waktu kontrol di bawah 1 bulan, 11 pasien mengkonsumsi obat dengan kombinasi antihipertensi lainnya dan 8 kasus tidak memiliki datarekam medis yang lengkap. Dari 139 subyek penelitian tersebut, terdapat 76 subyek yang menggunakan obat generik, sedangkan subyek 
penelitian yang menggunakan amlodipin bermerk sebanyak 63 orang sesuai dengan tabel 1 .

Tabel 1. Karakteristik Subjek

\begin{tabular}{lc}
\hline \multicolumn{1}{c}{ Karakteristik } & $\mathbf{N}(\%)$ \\
\hline Usia (tahun) & $55(39,6)$ \\
$>59$ & $83(59,7)$ \\
$30-59$ & $1(0,7)$ \\
$<30$ & \\
Jenis Kelamin & $58(41,7)$ \\
Laki-laki & $81(58,3)$ \\
Perempuan & \\
Obat Generik/Merk & $76(54,7)$ \\
Generik & $63(45,3)$ \\
Merk & \\
Indeks Massa Tubuh & $5(3,6)$ \\
Kurus & $35(25,2)$ \\
Normal & $29(20,9)$ \\
Overweight & $54(38,8)$ \\
Obesitas 1 & $16(10,8)$ \\
Obesitas 2 & \\
Dosis & $62(44,6)$ \\
5 mg & $77(55,4)$ \\
10 mg & \\
\hline &
\end{tabular}

Berdasarkan tabel 2, dapat dinyatakan tidak ada perbedaan yang bermakna penggunaan amlodipine generik maupun bermerek pada pasien berdasarkan derajat hipertensinya. Sebaliknya, terdapat perbedaan penggunaan amlodipine yang signifikan pada pasien berdasarkan jenis penggunaan jaminan kesehatannya. Pasien yang memperoleh jaminan kesehatan dari perusahaan dinyatakan memiliki proporsi terbesar menggunakan amlodipine bermerek.

Dalam penelitian ini, tidak diperoleh perbedaan yang signifikan antara usia, tekanan darah baik sistolik maupun diastolik awal dan akhir, serta penurunan tekanan darah sistolik dengan pengunaan amlodipine bermerk dan generik ( $p$-value >0.05). Di sisi lain, terdapat perbedaan penurunan tekanan darah diastolik (TDD) yang signifikan antara peng- gunaan amlodipine bermerek dan generic, dimana penurunan TDD lebih besar terpantau pada pasien yang menggunakan amlodipine generik.

Adapun dalam studi ini, diperoleh perbedaan yang signifikan antara rata-rata biaya pemberian amlodipin generikdan bermerk dengan harga lebih tinggi dimiliki oleh amlodipine bermerek ( $p$-value $<0,05)$. Di samping itu, tidak terdapat perbedaan penurunan tekanan darah pada pemberian obat amlodipin generik maupun bermerk yang dapat dilihat pada tabel 3 .

Tabel 3. Analisis Bivariat Perbedaan Penurunan Tekanan Darah (tercapai dan tidak) antara Penggunaan Amlodipine Generik dan Bermerk

\begin{tabular}{lcccc}
\hline Variabel & $\begin{array}{c}\text { Penurunan TD Tercapai } \\
(\mathbf{n}=\mathbf{8 3})(\mathbf{n}(\%))\end{array}$ & $\begin{array}{c}\text { Penurunan TD Tidak } \\
\text { Tercapai }(\mathbf{n}=\mathbf{5 6})(\mathbf{n}(\%))\end{array}$ & Total & p-value \\
\hline Generik & $27(32,5)$ & $36(64,3)$ & 63 & 0,606 \\
Bermerk & $29(34,9)$ & $47(83,9)$ & 76 & \\
\hline
\end{tabular}

Dengan tidak terobservasinya perbedaan penurunan tekanan darah yang diinginkan, reratabiaya pengobatan dengan amlodipin generik disadari lebih terjangkau, yakni sebesar Rp 68.660,- per bulan dibandingkandengan amlodipin bermerk seharga Rp 374.844,- atau sekitar 5,4 kali lebih tinggi dari amlodipin generik.

\section{Pembahasan}

Dalam studi ini, diperoleh hasil usia penderita hipertensi didominasi oleh usia antara 30-59 tahun. Hasil sejalan dengan penelitian Indonesian Society of Hypertension tahun 2007, secara umum prevalensi hipertensi di Indonesia pada orang dewasa berumur lebih dari 50 tahun antara 15\% - 20\%. Menurut Dede Kusmana dari departemen kardiologi Universitas Indonesia tahun 2007, usia penderita hipertensi antara 20-30 tahun prevalensinya adalah 5\% - 10\%, usia dewasa muda prevalensinya antara $20 \%-25 \%$ dan usia di atas 50 tahun sekitar $60 \%$.

Tabel 2. Distribusi Penggunaan Obat Generik dan Bermerk berdasarkan Derajat Hipertensi dan Jaminan Kesehatan.

\begin{tabular}{lccc}
\hline \multicolumn{1}{c}{ Karakteristik } & N (\%) & Generik (n (\%)) & Bermerk (n (\%)) \\
\hline Derajat Hipertensi & $78(56,1)$ & $40(51,3)$ & $38(48,7)$ \\
Derajat 1 & $61(43,9)$ & $36(59,0)$ & $25(41,0)$ \\
Derajat 2 & & & $29(34,5)$ \\
Jaminan Kesehatan & $84(60,4)$ & $55(65,5)$ & $28(75,7)$ \\
Umum & $37(26,6)$ & $9(24,3)$ & $6(39,3)$ \\
Perusahaan & $18(12,9)$ & $12(66,7)$ & 0,000 \\
Asuransi Swasta &
\end{tabular}


Tabel 4. Perbedaan Pengaruh Amlodipine Generik dan Bermerk terhadap Usia dan Tekanan Darah Sistolik dan Diastolik

\begin{tabular}{lccccc}
\hline Variabel & Generik & Bermerk & \multicolumn{2}{c}{ Nilai } & \multirow{2}{*}{ p-Value } \\
\cline { 4 - 5 } & Mean \pm SD & Mean \pm SD & Min & Max & \\
\hline Usia (tahun) & $59,6 \pm 10,8$ & $58 \pm 10,7$ & 22 & 79 & 0,551 \\
Tekanan Darah Sistolik (TDS) Awal (mmHg) & $154,1 \pm 20$ & $153,9 \pm 23,2$ & 140 & 210 & 0,963 \\
Tekanan Darah Diastolik (TDS) Awal (mmHg) & $89,5 \pm 11,4$ & $86,2 \pm 8,5$ & 70 & 120 & 0,059 \\
Tekanan Darah Sistolik (TDS) Akhir (mmHg) & $136,3 \pm 20,2$ & $143,1 \pm 23,6$ & 102 & 201 & 0,231 \\
Tekanan Darah Diastolik (TDS) Akhir (mmHg) & $81,2 \pm 9,6$ & $82,8 \pm 8,8$ & 56 & 109 & 0,175 \\
Penurunan Tekanan Darah Sistolik (TDS) (mmHg) & $17,8 \pm 25,7$ & $11,8 \pm 21,5$ & -40 & 70 & 0,160 \\
Penurunan Tekanan Darah Diastolik (TDD) (mmHg) & $8,3 \pm 12,6$ & $3,42 \pm 9,6$ & -21 & 40 & $0,010^{*}$ \\
Biaya (Rp) & $68,660 \pm 17,428$ & $374,844 \pm 146,950$ & 46,620 & 539,220 & $0,001^{*}$ \\
\hline
\end{tabular}

* = berbeda secara signifikan $(\mathrm{p}$-value $<0.05)$

Menurut penelitian yang dilakukan Suyati (2005) di RS Islam Jakarta, penderita hipertensi umumnya berusia antara 36-50 tahun yaitu sekitar 56,7 persen. Sementara penelitian Rasmaliah dkk (2005) di desa Pekan Labuhan dan nelayan Indah Kecamatan Medan Labuhan mencatat bahwa penderita hipertensi terbanyak pada usia 45-60 tahun sebesar 30,8 persen. Survei faktor resiko penyakit kardiovaskuler oleh WHO di Jakarta menunjukkan prevalensi hipertensi berdasarkan jenis kelamin dengan tekanan darah 160/90 mmHg pada pria tahun 2000 sebesar 12,1 persen. Sedangkan pada wanita prevalensi tahun 2000 sebesar 12,2 persen.

Amlodipine telah terbukti menjadi agen antihipertensi yang efektif pada orang tua (Pascual, 2000). Amlodipine merupakan agen yang berharga untuk mengobati hipertensi. Hasil uji klinis mendukung penggunaan amlodipine pada orang tua, termasuk yang $>75$ tahun. Sesuai dengan berbagai pedoman pengobatan untuk hipertensi, amlodipine harus dimulai pada dosis lazim dewasa $(5 \mathrm{mg}$ / hari) pada pasien usia lanjut.

Hubungan antara penggunaan amlodipin generik dan bermerk pada penurunan tekanan darah tidak signifikan dimana nilai $\mathrm{p}>0.05$. Hal ini berarti amlodipin generik dan bermerk sama-sama menurunkan tekanan darah secara bermakna namun tidak ada perbedaan signifikan dalam pencapaian penurunan tekanan darah.

Hasil penelitian didukung dengan penelitian Park et al, 2004 yang melakukan studi bioekivalensi dengan membandingkan Norvasc dengan amlodipin camsylate, dan didapatkan penurunan tekanan darah yang bermakna pada kedua grup tanpa perbedaan bermakna terhadap kadar elektrolit, pemeriksaan darah tepi, denyut jantung dan elektrokardiogram
( $>0.05)$. Hal tersebut didukung juga oleh penelitian lain yang dilakukan oleh Mignini et al (2007), dan Manzoli et al (2015)

Rerata biaya pengobatan dengan amlodipin generik 68.660 per bulan sedangkan dengan amlodipin bermerk sebesar 374.844 atau sekitar 5,4 kali lebih tinggi dari amlodipin generik.Dengan demikian biaya pengobatan dengan amlodipin generik akan memakan biaya sejumlah Rp 823.920,-, dalam 5 tahun ke depan biaya akan mencapai sekitar Rp 4.119.600,-. Biaya untuk amlodipin bermerk sebesar Rp 4.498.128,- dalam 5 tahun ke depannya akan mencapai sekitar Rp 22.490.640,-

Perubahan pola pembayaran dari konsep FFS ke paket INA-CBG's menyebabkan pasien yang tadinya mendapat kebebasan dalam pemberian obat, dengan sendirinya tidak dapat lagi diberikan dan harus beralih ke obat generik sesuai dengan kebijakan RS yang diberlakukan bagi pasien JKN untuk menyesuaikan dengan tarif paket INA-CBG's rawat jalan yang ditetapkan oleh Pemerintah. Hal ini menimbulkan keluhan dari pasien-pasien tersebut sehingga menyebabkan beberapa perusahaan memutuskan untuk menambah manfaat dengan mengikuti program Top Up. Namun pada kenyataannya manajemen perusahaan juga tidak mau dirugikan dengan sejumlah besar premi yang mereka bayarkan ke pihak BPJS sebagai pengelola JKN, dan dengan demikian manajemen perusahaan meminta agar penggunaan formularium nasional diprioritaskan seoptimal mungkin untuk meminimalisasi selisih bayar yang timbul.

Dengan adanya tuntutan seperti di atas menyebabkan aspek biaya menjadi pertimbangan yang sangat penting dalam menyusun formularium RS. Jika manajemen RS tidak melakukan reformasi dalam 
penyusunan formularium maka RS memiliki potensi kehilangan pasien-pasien perusahaan yang menggunakan Top Up maupun Coordination of Benefit (COB) dengan BPJS.

Manajemen RS perlu melibatkan dokter maupun Komite Farmasi Terapi RS untuk melakukan perubahan terhadap penyusunan formularium dengan memperhatikan aspek biaya mengingat keluaran dari amlodipin generik dan bermerk tidak ditemui adanya perbedaan bermakna. Diperlukan kesamaan visi dan persepsi agar dokter mau melihat unsur kepentingan manajemen RS dan juga kepentingan pasien dalam melakukan pelayanan kepada pasien.

\section{Kesimpulan dan Saran \\ Kesimpulan}

Berdasarkan hasil penelitian, dapat ditarik kesimpulan bahwa penggunaan amlodipin generik lebih banyak dibandingkan penggunaan obat bermerk di Poli Jantung dan Penyakit Dalam RS X Pekanbaru selama tahun 2015. Penggunaan generik didominasi oleh pasien umum dibandingkan pasien jaminan asuransi swasta dan perusahaan. Selain itu, diperoleh hasil bahwa penggunaan amlodipin generik maupun bermerk menurunkan tekanan darah secara bermakna, namun tidak terdapat perbedaan bermakna antara penurunan tekanan darah yang dicapai dengan pemberian amlodipin generik maupun amlodipin bermerk.

Dari hasil studi ini, didapatkan rerata biaya pengobatan dengan amlodipin generik adalah sebesar Rp 68.660,- per bulan sedangkan dengan amlodipin bermerk sebesar Rp 374.844,- atau sekitar 5,4 kali lebih tinggi dari amlodipin generik. Dengan demikian, amlodipin generik merupakan pilihan yang efisien dalam menurunkan tekanan darah dan memiliki biaya yang lebih efisien dibandingkan dengan amlodipin bermerk.

\section{Saran}

Berdasarkan studi ini, beberapa saran dapat dikemukakan, di antaranya:

\section{Untuk Rumah Sakit X Pekanbaru}

a. Rumah Sakit X dapat melakukan penelitian serupa untuk menganalisis biaya dengan menggunakan metode evaluasi ekonomi untuk obat-obat yang lain yang akan diajukan dalam penyusunan formularium rumah sakit.

b. RS X dapat mengubah kebijakan dan prosedur terkait penetapan formularium yang me- wajibkan obat originator, copydrug maupun generik, mengutamakan kualitas obat serta memasukkan analisis biaya dalam setiap penyusunan formularium.

c. Manajemen rumah sakit dilibatkan secara mendalam dalam penyusunan formularium RS, bersama dengan Komite Farmasi dan Terapi.

d. Manajemen RS X dapat mengusulkan anggaran untuk pengembangan sumber daya manusia terutama bagi dokter spesialis. Selama ini, anggaran pelatihan baru disediakan bagi karyawan RS. Oleh karena status kepegawaian dokter spesialis bukan sebagai karyawan RS namun sebagai mitra RS.

e. Manajemen RS selain melakukan penilaian terhadap kepatuhan dokter dan dokter spesialis terhadap penggunaan formularium, juga dapat memberlakukan sistem reward and punishment terhadap kepatuhan penggunaan formularium.

2. Bagi asuransi kesehatan maupun perusahaan yang bekerjasama dengan RS X Grup

Melakukan edukasi kepada karyawan mengenai efikasi dan efektivitas obat generik maupun bermerk berdasarkan hasil kajian penilaian teknologi kesehatan terhadap obat antihipertensi, dimana hal ini akan memberikan informasi yang obyektif berbasis bukti mengenai efektivitas dan efisiensi biaya dari beberapa merk obat antihipertensi yang tersedia sehinggadengan demikian pihak penjamin akan diuntungkan dari segi biaya.

\section{Bagi BPJS Kesehatan}

Melakukan penelitian biaya dan hubungan obat antihipertensi amlodipin terhadap antihipertensi kombinasi lainnya yang diberikan oleh dokter kepada pasien yang tidak tercapai penurunan tekanan darah hanya dengan pemberian amlodipin tunggal.

\section{Daftar Pustaka}

Consumer Union of US, 2011. Using Calcium Channel Blockers to Treat High Blood Pressure and Heart Disease Comparing Effectiveness, Safety and Rice. Consumerreporthealth.org/bestbuydrugs. p:2

Departemen Kesehatan RI, Jakarta. Desember 2009. Maj Kedokt Indon, Volume: 59, Nomor: 12.hal :581-583

Drug Information Handbook with International Trade Names Index 19th edition. 2010 - 2011. p : 106 
$-107$

Drummond et al., MF, Stoddart GL., Torrance GW., 1997. Methods for the Economic Evaluation of Health Care Programmes. Oxford University Press.

Joint National Commitee 7, 2003. The Seventh Report of the Joint National Commiittee on Prevention, Detection, Evaluation, and Treatment of High Blood Pressure. $\mathrm{p}: 11$

Joint National Committee 8. 2008. JNC 8 Guidelines for the Management of Hypertension in Adults.

Kesselheim AS, Misono AS, Lee JL, Stedman MR, Brookhart MA, Choudry NK, et al., 2008. Clinical equivalence of generic and brand-name drugs used in cardiovascular disease: a systematic review and meta-analysis. JAMA 300(21):2514-26.

Kim SH, Kim YD, Lim DS, Yoon MH, Ahn YK, On YK, et al., 2007. Korean Multicenter Amlodipine Study Investigators. Results of a phase III, 8-week, multicenter, prospective, randomized, double-blind, parallel-group clinical trial to assess the effects of amlodipine camsylate versus amlodipine besylate in Korean adults with mild to moderate hypertension. Clin Ther 29(9):1924-36.

Manzoli L, Flacco Elena, D’Andrea E, Panic N et al., 2015. Generic versus brand-name drugs used in cardiovascular diseases. Eur J Epidemiol. DOI 10.1007/s10654-015-0104-8.

Mignini F, Tomassoni D, Traini E, Amenta F., 2007. Singledose,randomized, crossover bioequivalence study of amlodipine maleate versus amlodipine besylate in healthy volunteers. Clin Exp Hypertens $29(8): 539-552$.
Park JY, Kim KA, Lee GS, et al., 2004. Randomized, openlabel, two-period crossover comparison of the pharmacokinetic and pharmacodynamic properties of two amlodipine formulations in healthy adult male Korean subjects. Clin Ther;26(5):715723.

Pedoman Penerapan Kajian Farmakoekonomi.Kementrian Kesehatan RI. Direktorat Jenderal Bina Kefarmasian dan Alat Kesehatan. 2012. Jakarta: $6,8,9,13,14$

Pedoman Hipertensi Departemen Kesehatan, 2006. Pusat Data dan Informasi Kementrian Kesehatan RI tentang Hipertensi. hal :1-6

Pedoman Uji Bioekivalensi, 2005. Badan Pengawas Obat dan Makanan Republik Indonesia. Jakarta. pp 3-8.

Perhimpunan Hipertensi Indonesia, 2007. Konsensus Hipertensi vol.6 No.7. hal :2

Qais alefan, M Izham, M Ibrahim et al., 2009. Asian Journal of Pharmaceutical and Clinical Research.. Cost of Treating Hypertension in Malaysia. Volome 2. Isssue 1. pp: 1-3.

Riset Kesehatan Dasar, 2013. Badan Penelitian dan Pengembangan Kesehatan Kementrian Kesehatan RI. Jakarta.

Undang-Undang Republik Indonesia Kesehatan no 36 tahun 2009 tentang Kesehatan.

Walley T, Haycox A, Bolond A., 2004. Pharmacoeconomics. Churchill Livingstone.Oxford.

WHO-ISH Hypertension Guideline Committee. 1999. Guidelines of the management of hypertension. J Hypertension. 